\title{
Response to Letter to the Editor from Jan-Uwe Schreiber, MD and Thomas Fuchs-Buder, MD, PhD; Succinylcholine: the Dilemma with the Evidence
}

\author{
Amir Mehran
}

Received: 7 September 2009 / Accepted: 22 September 2009 / Published online: 16 October 2009

(C) The Author(s) 2009. This article is published with open access at Springerlink.com

We appreciate the author's feedback. We have discussed their comments with our primary bariatric anesthesia group. Based on their clinical experience, 30 years in one case, they do not believe lidocaine to be very effective in eliminating the fasciculations from succinylcholine (SUX), and consequently postoperative myalgias. Rocuronium (ROC), on the other hand, is effective in eliminating the fasciculations, but it is painful on injection which is not easily prevented by lidocaine. They still prefer using ROC or other nondepolarizing agents for rapid sequence inductions with complete success. The difference in onset between SUX and ROC is 1-2 min which they consider trivial compared to the time taken to accomplish the intubation. Furthermore, if one prevents active vomiting by excellent anesthesia and paralysis, and passive regurgitation by "correct" cricoid pressure, then the amount of time required for intubation is no longer critical. To quote them directly: "The word 'rapid' in rapid sequence induction is one of the worst words in the lexicon of anesthesia". Their preference is for "safe sequence inductions" so that time is no longer relevant.

From a surgeon's standpoint, the additional side effects of SUX (as outlined in our paper) are of equal concern in this particular patient population. We agree that one case may not define the entire practice. However, when better drugs are available with a more favorable overall profile, we also don't see the need to use SUX instead of ROC.

Open Access This article is distributed under the terms of the Creative Commons Attribution Noncommercial License which permits any noncommercial use, distribution, and reproduction in any medium, provided the original author(s) and source are credited.
(Comment on our original submission)

1. Tejirian T, Lewis CE, Conner J et al (2009) Succinylcholine: a drug to avoid in bariatric surgery. Obes Surg 19: 534-6.)

A. Mehran $(\bowtie)$

UCLA,

Los Angeles, California, USA

e-mail: amehran@mednet.ucla.edu 